\title{
Neural Network Based Field Oriented Control for Doubly-Fed Induction Generator
}

\author{
Mohamed Hallouz*, Nadir Kabache*, Samir Moulahoum**, Selman Kouadria** \\ *Research Laboratory of Electrical Engineering \& Automatic, LREA, University of Médéa, Algeria \\ **LCP, Process Command Laboratory, National Polytechnic School of Algiers, Algeria \\ (hallouz.mohamed@yahoo.fr, nadir.kabache@gmail.com, samir.moulahoum@gmail.com,kouadria.selman@gmail.com) \\ ${ }^{\ddagger}$ Corresponding Author
}

Received: 16.08.2018 Accepted:29.09.2018

\begin{abstract}
The present research paper deals with a study of a variable speed wind energy conversion system (VSWECS) based on a Doubly Fed Induction Generator (DFIG), the stator is directly connected to the grid and driven by climbed back-to-back converters. Direct control of DFIG with a variable structure based on an artificial neural network is presented. Artificial Neuronal Network ANN is proposed to improve performances and to substitute the classical PI regulators in the direct control of active and reactive powers of the DFIG. The performance of the approach has been tested and validated by simulation for different operating conditions. Simulation results and improvement of the behavior of the DFIG are presented, using Matlab/Simulink software.
\end{abstract}

Keywords: DFIG; RSC; Artificial Neural Network; Traditional PI; Wind energy.

\section{Introduction}

The doubly-fed induction generator has a very important role in the field of electric power generation in wind farms [1]. This type of machine can operate in motor mode as it can operate in generator mode without requiring specific constraints on the value of the speed. This advantage allows the DFIG to operate for a large speed range unlike the synchronous generator that requires a well determined synchronism speed.

The speed variation of DFIG operation requires the use of two frequency converters, one for the stator side and the other for the rotor side to adapt the energy flow exchanged between the DFIG and the electric grid. For this purpose, effective control laws are necessary to control the operation of the DFIG, in particular, when we add the very complicated dynamic behavior of this machine [1], [2].

Since it used in the wind systems, many techniques have been proposed to control the active and reactive power of the DFIG. The most important techniques are only modified versions of those developed for the control of the torque and flux in motor operation of the DFIG. So, we find the vector control of the power and the direct control of power
The use of these control schemes improves the performance of the DFIG in wind systems. However, these techniques have certain constraints such as the complexity of the control algorithms, the sensitivity to the parametric variations of the system, the important processing time [3].

To remedy these constraints, in the present work we propose to use artificial neural networks to simplify and improve the direct vector control scheme of the active and reactive powers of the DFIG. Indeed, a simple ANN is used to replace the two PI regulators used in the scheme of the vector control. The learning of the ANN is performed using the back propagation algorithm and a database has obtained from the performances completed by the standard PI regulators.

The proposed control scheme has been tested and validated for different operating conditions. In addition to the simplicity of this control scheme, the results obtained are satisfactory and even improved compared to those obtained by the standard vector control.

\section{Vector Control Strategy}

The structure of the DFIG is peculiar because it has two channels of power exchange with the power grid. The variable speed operation of the wind systems requires the DFIG to be equipped with two frequency converters to 
link it with the electrical network on the stator and rotor sides (Fig.1) [4]. For this purpose, the control scheme of a DFIG is quite complicated. The first control attempts were inspired by the diagrams developed for the motor operation of this machine such as vector control [5].

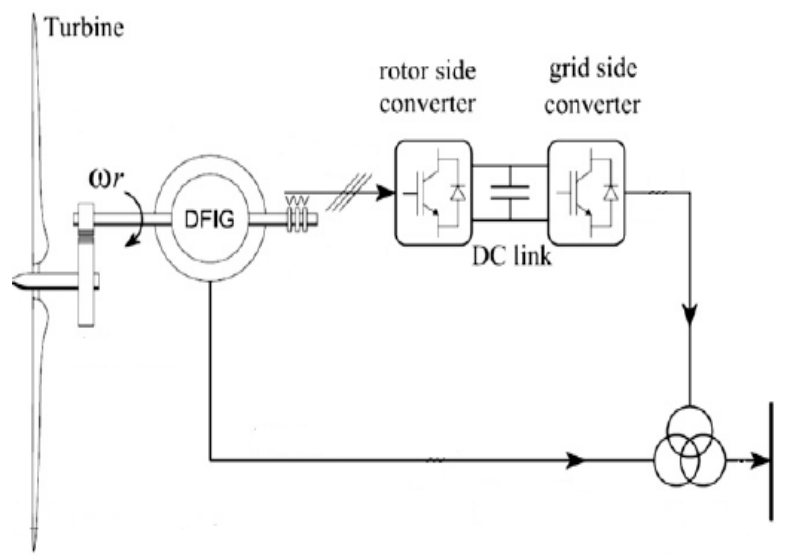

Fig. 1. DFIG based Model

It should be noted that vector control has been proposed for asynchronous induction motors in order to find a decoupling between the torque and the flux so that they are regulated separately by the direct and indirect components of the stator or rotor currents of the motor. Inspired by this principle, modified versions of the vector control have been proposed to separately control the active and reactive powers of a DFIG [5], [6].

By considering the model of the DFIG in the reference frame related to the rotating field, the principle of the vector control consists to orient the stator flux vector to the direct axis of the rotating reference frame (Fig.2) [7].

$\varphi_{s}=\varphi_{d s,} \varphi_{q s}=0$

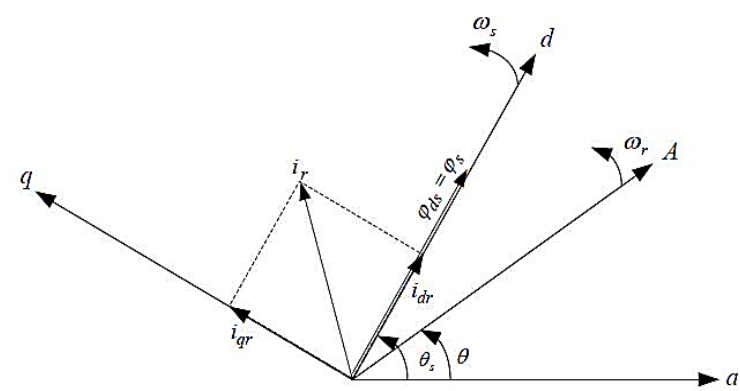

Fig. 2. Flux orientation

This gives for the voltages on the stator side:

$$
V_{d s}=0, V_{q s}=V_{s}
$$

And for rotor side voltages, they are given by:

$$
\left\{\begin{array}{c}
V_{d r}=R_{r} I_{d r}+\frac{d\left(L_{r}-\frac{M^{2}}{L_{s}}\right) I_{d r}}{d t}-g W_{s}\left(L_{r}-\frac{M^{2}}{L_{s}}\right) I_{g r} \\
V_{g r}=R_{r} I_{g r}+\frac{d\left(L_{r}-\frac{M^{2}}{L_{s}}\right) I_{g r}}{d t} I_{q r}-g W_{s}\left(L_{r}-\frac{M^{2}}{L_{s}}\right) I_{d r}+g \frac{M_{s}}{L_{s}}
\end{array}\right.
$$

Under these conditions, the active and reactive powers can be expressed by:

$$
\left\{\begin{array}{c}
P_{s}=-\frac{V_{s} M}{L_{s}} I_{q r} \\
Q_{s}=\frac{V_{s}^{2}}{w_{s} L_{s}}-\frac{V_{s} M}{L_{s}} I_{d r}
\end{array}\right.
$$

Considering the equations (3) and (4), the model of the DFIG can be arranged under the structure shown in the Figure. 3.

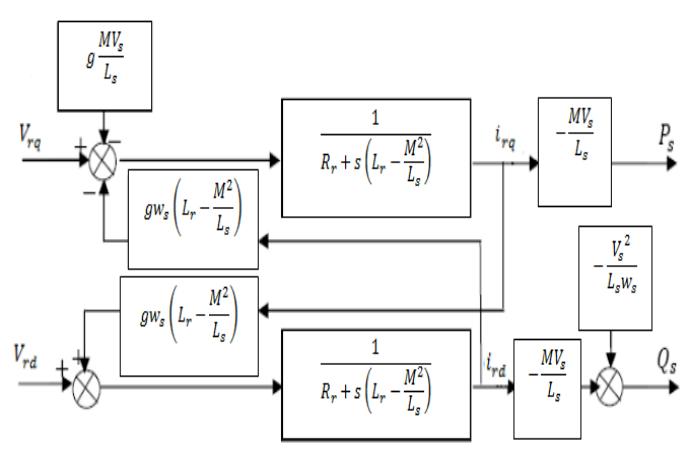

Fig. 3. Block diagram of the DFIG model to be regulated

From the block diagram of the DFIG (Fig. 3), two PI regulators are used to separately control the active and reactive powers according to the principle of direct vector control. This method is called direct method because the regulators directly control the powers. The diagram of the resulting command is given in the Figure. 4.

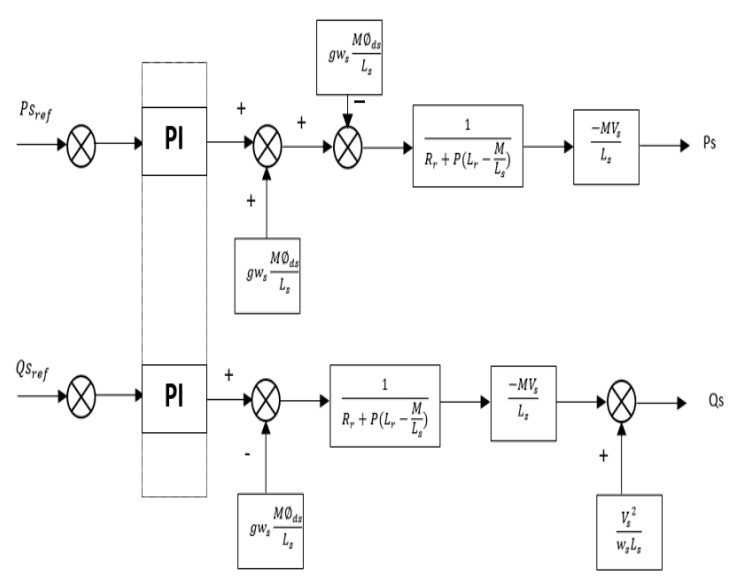

Fig. 4. Control of the powers with the PI regulator 


\section{Artificial Neural Network Strategy From The DFIG}

Inspired by the structure of the human brain system, an artificial neural network is a set of neurons linked together by weighted connections and has a set of activation functions to assign it a certain dynamic behavior that is generally non-linear. The neural procedure allows identification between the inputs and outputs of a nonlinear system while performing two simple arithmetic operations, the weighted sum of its inputs and the application of a non-linear activation function on the result of this sum [8], [9].

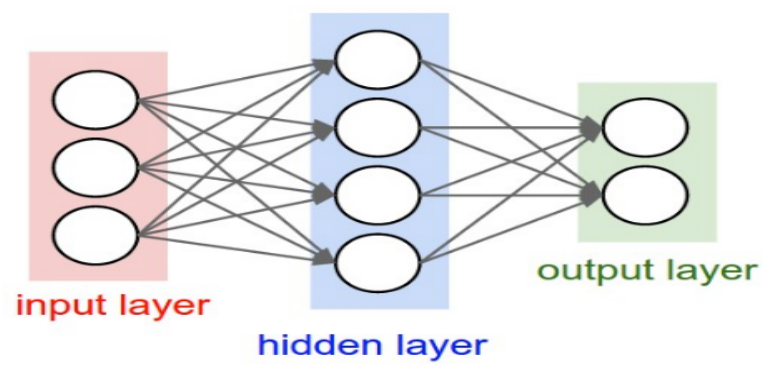

Figure 5. The proposed ANN

ANN has particulars characteristics, such as parallel operation, learning ability, and generalization capability. These characteristics have enabled ANNs to be, during the last decades, one of the most powerful means of estimation for control systems in different fields of application [8], [10].

The operation of the neural network is represented by the following functions:

$$
y=\sum_{k=1}^{n} w_{k}^{2} g\left(\sum_{j=1}^{p} w_{k j}^{1} \varphi_{j}+b_{k}^{1}\right)+b^{2}
$$

With:

\section{$\varphi_{j}:$ ANN inputs}

$w_{k j}^{1}$ et $b_{k}^{1}$ : The weights and the bias of the hidden layer

$g(x)=\frac{2}{1+e^{-2 x}}-1:$ The sigmoid function

$w_{k}^{2}$ et $b^{2}$ : The weights and biases of the output neuron

To take advantage of its advantages, an ANN is proposed in this article to simplify and improve the vector control scheme of the DFIG. The proposed ANN is used to replace the two PI regulators in Fig. 4. For the learning of the ANN, it is done offline using a database obtained from the standard vector control diagram. To do this, the inputs and outputs of the PI controllers are read during the simulation of the vector control for different operating conditions. Then, these data are processed to select a learning base of an appropriate size to ensure a compromise between the sought accuracy and the learning and computing time [4], [11]. Learning is done using the famous retro-propagation algorithm.

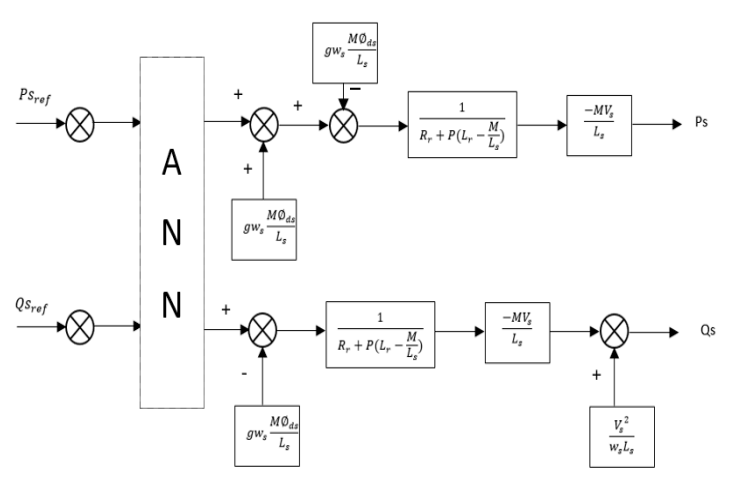

Fig. 6. Control of the powers with the ANN regulator

\section{Simulation Results}

To check the performance of the proposed neural network regulator, it has been introduced into the control circuit and tested for different operating conditions.

The results obtained clearly show, despite the size reduced of the used learning base, with its ability to generalize, the ANN can faithfully imitate the performance of the two regulators. In addition, there is important improvement in the performance of the DFIG, particularly in transient regimes.

Fig. 7 shows the results for the active and reactive powers obtained by the PIs and by the proposed ANN. In all operating conditions, both powers follow their reference with slight disturbances due to commutations in the converter. Peaks in the transient regimes are not important in the case of the ANN unlike the PI controllers. The same conclusions are observed for the rotor currents (Fig 9).
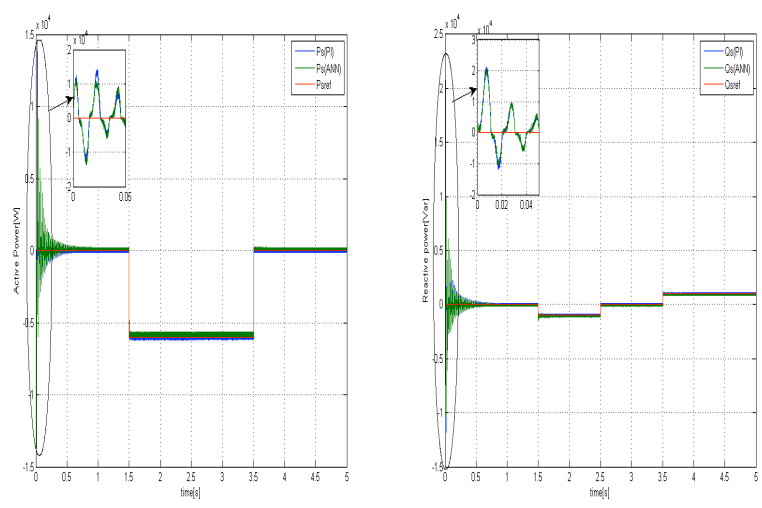

Figure 7.Active and Reactive powers 

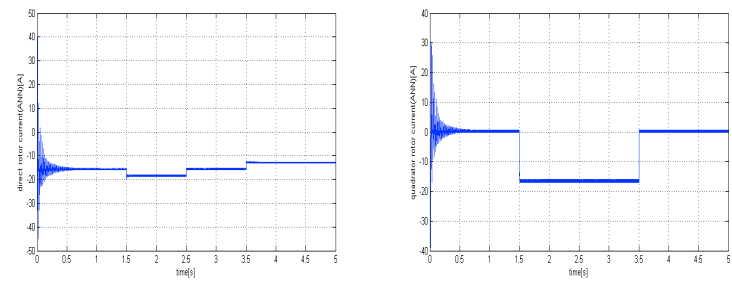

(a)
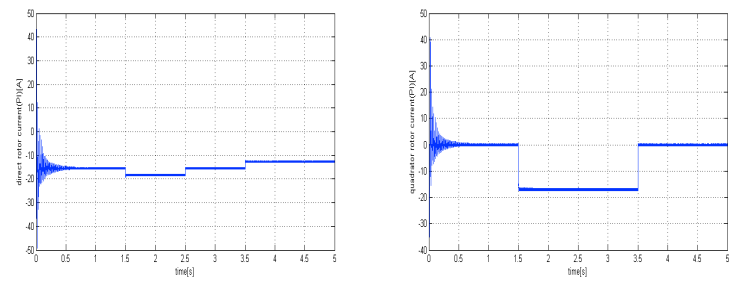

(b)

Fig. 8. Direct and Quadrature rotor current (a) ANN control; (b) PIs control

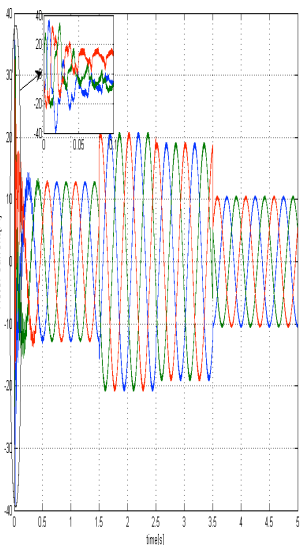

(a)

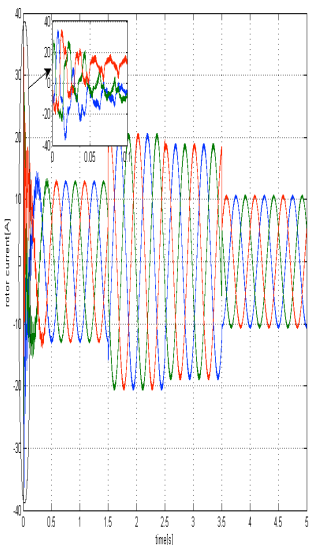

(b)
Figure 9. Three phases rotor current (a) obtained with PIs control; (b) obtained with ANN control
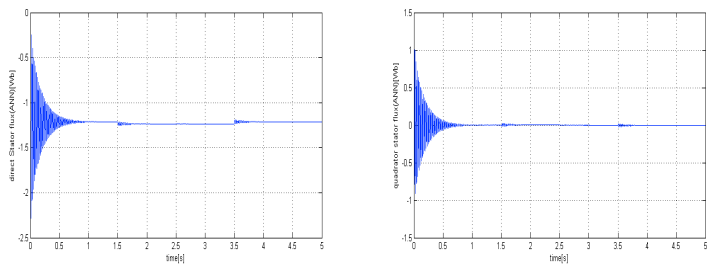

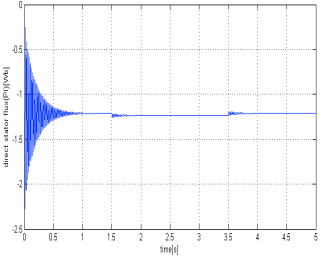

(a)

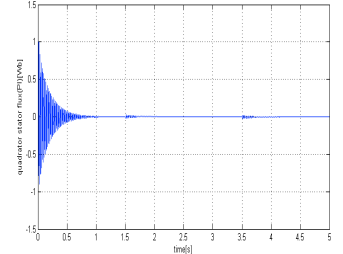

(b)
Fig. 10. Stator flux (a) direct stator flux; (b) quadrator stator flux

\section{Conclusion}

In this paper, a neural regulator to simplify the vector control scheme of a DFIG was proposed. After appropriate learning, the proposed regulator has provided satisfactory performance for different operating conditions. The results obtained make it possible to extend the perspectives towards an experimental validation of the proposed neural regulator and towards a wider use of the ANN in the control scheme of the DFIG, in particular, with an online learning.

\section{References}

[1] F. Akel, T. Ghennam, E. M. Berkouk, et M. Laour, "An improved sensorless decoupled power control scheme of grid connected variable speed wind turbine generator", Energy Convers. Manag., vol. 78, p. 584594, févr. 2014.

[2] A. Moualdia, M. Mahmoudi, L. Nezli, et O. Bouchhida, "Modeling and Control of a Wind Power Conversion System Based on the Double-Fed Asynchronous Generator ", Int. J. Renew. Energy Res. IJRER, vol. 2, no 2, p. 300-306, mai 2012.

[3] S. Kouadria, Y. Messlem, et E. M. Berkouk, " Sliding mode control of the active and reactive power of DFIG for variable-speed wind energy conversion system ", in 2015 3rd International Renewable and Sustainable Energy Conference (IRSEC), 2015, p. 1-8.

[4] Y. Djeriri, A. Meroufel, et M. Allam, “ Artificial neural network-based robust tracking control for doubly fed induction generator used in wind energy conversion systems ", J. Adv. Res. Sci. Technol., vol. 2, no 1, p. 173-181, janv. 2015.

[5] B. Bossoufi et al., "Robust adaptive Backstepping control approach of DFIG generators for wind turbines variable-speed ", in 2014 International Renewable and Sustainable Energy Conference (IRSEC), 2014, p. 791797.

[6] K. Siraj, H. Siraj, et M. Nasir, " Modeling and control of a doubly fed induction generator for grid integrated wind turbine", in 2014 16th International Power Electronics and Motion Control Conference and Exposition, 2014, p. 901-906.

[7] K. Belgacem, A. Mezouar, et A. Massoum, " Sliding Mode Control of a Doubly-fed Induction Generator for Wind Energy Conversion", Int. J. Energy Eng., vol. 3, no 1, p. 30-36, 2013.

[8] B. Azeem et al., " Robust neural network scheme for generator side converter of doubly fed induction generator", in 2017 International Symposium on Recent Advances in Electrical Engineering (RAEE), 2017, p. 1-6.

[9] N. Kabache et S. Moulahoum, "Neural Network Estimator for Induction Motor Parameters". 4th 
International Conference on Electric Engineering ICEE'12, Alger, Algeria, 07-09 Mai 2012, pp. 449-454

[10] N. Kabache, S. Moulahoum, K. Sebaa, et H. Houassine, "Neural network based input output feedback control of induction motor", in Optimization of Electrical and Electronic Equipment (OPTIM), 2012 13th International Conference on, Romania, 2012, pp. 578-583.

[11] D. Youcef, " Direct power control based artificial neural networks of doubly fed induction generator for wind energy conversion system application", J. Adv. Res. Sci. Technol., vol. 5, no 1, p. 592-603, 2018.
[12] M. L. Said, S. Moulahoum, M. Bounekhla, N. Kabache and H. Houassine, "Autonomous operation of a doubly fed induction generator driven by a wind turbine", in 2015 20th International Conference on Methods and Models in Automation and Robotics (MMAR), Poland, 2015, p. 1050-1055.

[13] A. Adouni, D. Chariag, D. Diallo, M. Ben Hamed, and L. Sbita, "FDI based on Artificial Neural Network for Low-Voltage-Ride-Through in DFIGbased Wind Turbine", ISA Trans., vol. 64, p. 353 364, sept. 2016.

[14] N. Kabache, S. Moulahoum, et H. Houassine, "FPGA Implementation of direct Rotor Field Oriented Control for Induction Motor ", in Methods and Models in Automation and Robotics (MMAR), 2013 18th International Conference on, Poland, 2013, pp. 485-489. 